\title{
Spontaneous rupture of a parastomal hernia with evisceration of small bowel: a case report
}

\author{
Oshan Basnayake ${ }^{1}$, Umesh Jayarajah ${ }^{1}$, Jayan Jayasinghe ${ }^{1}$, Pradeep Kumara Wijerathne ${ }^{1}$ and \\ Dharmabandhu Nandadeva Samarasekera ${ }^{2^{*}}$ (i)
}

\begin{abstract}
Background: Long standing ostomy related complications such as parastomal hernia and stoma prolapse may be at a higher risk of developing spontaneous rupture and evisceration, especially in patients suffering from chronic cough. Such patients may need early refashioning of the stoma to prevent this serious complication. Parastomal evisceration is a very rare complication of stomas and to date, only few cases have been reported in the literature.

Case presentation: A 51 year old patient with chronic obstructive pulmonary disease (COPD) and extensive hidradenitis suppurativa of the perineum underwent a temporary defunctioning loop sigmoid colostomy and subsequent perineal skin excision and skin grafting. The ostomy was complicated by a parastomal hernia and stoma prolapse 6 weeks post operatively. Five months later he developed spontaneous rupture of parastomal hernia and evisceration of small bowel. Urgent surgery was done and reduction of small bowel loops and re-siting of the sigmoid colostomy was done.
\end{abstract}

Discussion and conclusions: Parastomal evisceration is an extremely rare life threatening stoma-related complication which requires urgent treatment.

Keywords: Parastomal hernia, Spontaneous rupture, Evisceration, Sigmoid loop colostomy, Case report

\section{Background}

The creation of a permanent or temporary stoma is associated with varying complication rates ranging from 21 to $70 \%$ [1]. Common complications include ischaemia, skin irritation, retraction, prolapse and parastomal hernia and these are associated with poor quality of life and furthermore, can rarely present as emergencies [2].

Parastomal hernia occurs through an acquired defect of the abdominal wall due to a surgical incision which allows protrusion of abdominal viscera and the incidence differs with the type of intestinal stoma. The reported occurrence of parastomal hernia with loop colostomy is between $0-30.8 \%$ [3]. Similar to other abdominal hernias, patients can have complications such as irreducibility, obstruction and strangulation.

\footnotetext{
* Correspondence: samarasekera58@yahoo.co.uk

${ }^{2}$ Department of Surgery, Faculty of Medicine, University of Colombo, Kynsey Road, Colombo 8, Western Province, Sri Lanka

Full list of author information is available at the end of the article
}

Parastomal evisceration is an extremely rare complication with only few cases reported in the literature.

\section{Case presentation}

A 51 year old patient with chronic obstructive pulmonary disease (COPD) due to long term smoking and extensive hidradenitis suppurativa of the perineum underwent a temporary defunctioning loop sigmoid colostomy and subsequent extensive perineal skin excision and skin grafting.

The ostomy was complicated by a parastomal hernia and stoma prolapse 6 weeks post operatively. Conservative management was opted as the stoma was temporary and was functioning well. Five months later, while he was in hospital care for further excision of perianal skin and skin grafting, he developed acute onset pain at the stoma site with rupture of parastomal hernia and evisceration of small bowel loops (Fig. 1).There was no evidence of strangulation or intestinal obstruction.

(c) The Author(s). 2019 Open Access This article is distributed under the terms of the Creative Commons Attribution 4.0 International License (http://creativecommons.org/licenses/by/4.0/), which permits unrestricted use, distribution, and reproduction in any medium, provided you give appropriate credit to the original author(s) and the source, provide a link to the Creative Commons license, and indicate if changes were made. The Creative Commons Public Domain Dedication waiver (http://creativecommons.org/publicdomain/zero/1.0/) applies to the data made available in this article, unless otherwise stated. 


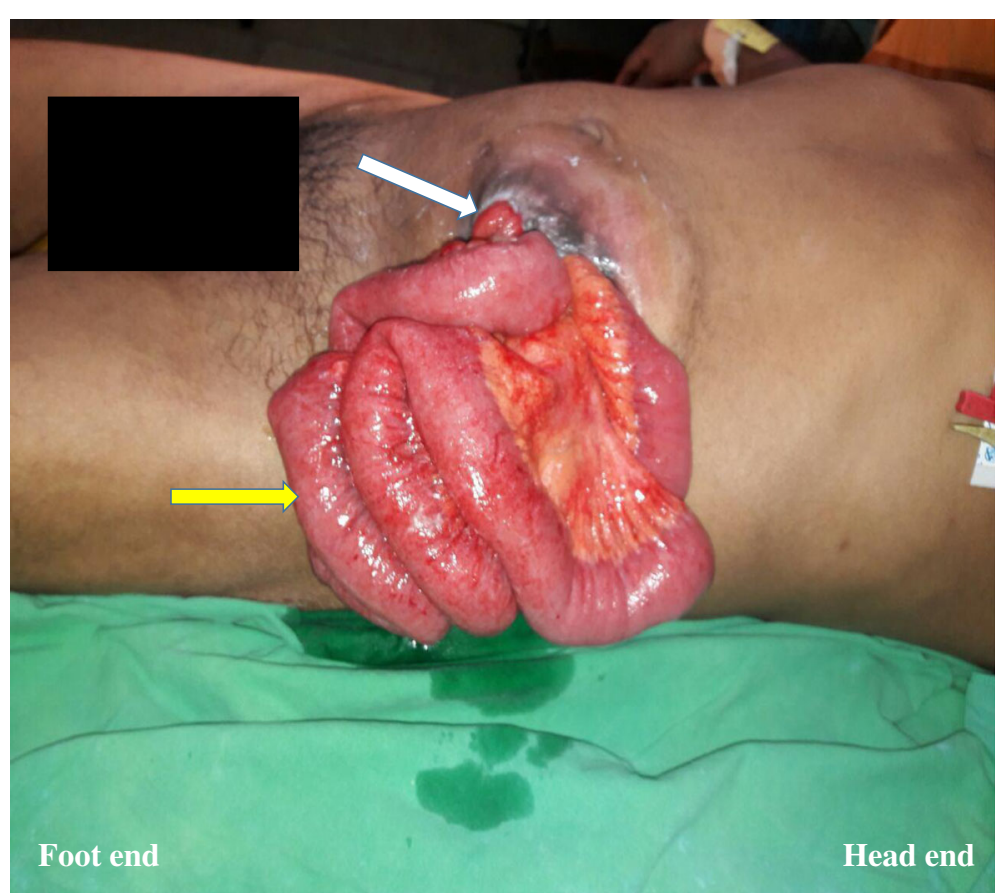

Fig. 1 White arrow shows the site of loop sigmoid colostomy and yellow arrow shows the eviscerated small bowel loops

Urgent surgery was done and reduction of small bowel loops and re-siting of the sigmoid colostomy was done. Post-operatively he had exacerbation of COPD which required intensive care management with positive pressure ventilation for 2 days. Thereafter, his recovery was uneventful.

\section{Discussion and conclusions}

Parastomal evisceration is a very rare complication of stomas and to date, only ten cases have been reported worldwide. Most of the previously published cases were associated with ileostomies [4-6] and four were reported in association with colostomies [7-10].The majority of the cases were associated with stoma prolapse or parastomal hernia and one within the immediate post-operative period [10].

In our patient, long term parastomal hernia and stoma prolapse may have caused ischaemia and weakening of the underlying abdominal wall and the overlying skin resulting in parastomal evisceration of small bowel. Furthermore, the increased abdominal pressure due to chronic cough(i.e. due to COPD) may have also contributed. Lolis et al. [7] reported a patient with similar contributory factors in a patient with a parastomal hernia and a chronic colostomy prolapse.

Parastomal evisceration is an extremely rare life threatening stoma-related complication which requires urgent treatment. Patients with COPD and long standing ostomy related complications such as parastomal hernia and stoma prolapse may be at a higher risk of developing this complication. Such patients may need early refashioning of the stoma to prevent this serious complication.

Abbreviations

COPD: chronic obstructive pulmonary disease

\section{Acknowledgements}

Not Applicable.

\section{Funding}

None declared.

Availability of data and materials

All data generated or analyzed during this study are included in this published article.

\section{Authors' contributions}

Author $\mathrm{OB}, \mathrm{UJ}, \mathrm{JJ}$, and PKW contributed to collection of information and writing of the manuscript. Author DNS contributed to writing and final approval of the manuscript. All authors have read and approved the manuscript.

Ethics approval and consent to participate Not applicable.

\section{Consent for publication}

Informed written consent for publication was obtained from the patient prior to collecting data.

Competing interests

The authors declare that they have no competing interests. 


\section{Publisher's Note}

Springer Nature remains neutral with regard to jurisdictional claims in published maps and institutional affiliations.

\section{Author details}

${ }^{1}$ Professorial Surgical Unit, National Hospital of Sri Lanka, Colombo, Sri Lanka.

${ }^{2}$ Department of Surgery, Faculty of Medicine, University of Colombo, Kynsey

Road, Colombo 8, Western Province, Sri Lanka.

Received: 5 February 2019 Accepted: 15 April 2019

Published online: 25 April 2019

\section{References}

1. Jayarajah U, Samarasekara AM, Samarasekera DN. A study of long-term complications associated with enteral ostomy and their contributory factors. BMC Res Notes. 2016;9(1):500

2. Jayarajah U, Samarasekera DN. A cross-sectional study of quality of life in a cohort of enteral ostomy patients presenting to a tertiary care hospital in a developing country in South Asia. BMC Res Notes. 2017;10(1):75.

3. Carne P, Robertson G, Frizelle F. Parastomal hernia. Br J Surg. 2003;90(7):784-93.

4. Arbra CA, Fann SA. Parastomal evisceration: rare complication after Total abdominal colectomy. Am Surg. 2017;83(9):E379.

5. Park S, Lee S, Lee K. Small bowel evisceration by rupture of prolapsed loop ileostomy. Color Dis. 2010;12(6):603-4.

6. Ramly E, Crosslin T, Orkin B, Popowich D. Strangulated ileostomy evisceration following lateralizing mesh repair of parastomal hernia. Hernia. 2016;20(2):327-30

7. Lolis E, Savvidou P, Vardas K, Loutseti D, Koutsoumpas V. Parastomal evisceration as an extremely rare complication of a common procedure. Ann R Coll Surg Engl. 2015;97(7):e103-4.

8. Villa M, lannelli E, Grande M, Rossi P, Tucci G. An unusual case of small intestine evisceration through a transverse loop colostomy. Color Dis. 2012; 14(1):e27-8.

9. Yucel AF, Pergel A, Aydin I, Sahin DA. A rare stoma-related complication: parastomal evisceration. Ind J Surg. 2014:76(2):154-5.

10. Azouz V, Simmons JD, Abourjaily GS. Immediate postoperative parastomal end sigmoid hernia resulting in evisceration and strangulation. J Surg Case Rep. 2014;2014(5).

Ready to submit your research? Choose BMC and benefit from:

- fast, convenient online submission

- thorough peer review by experienced researchers in your field

- rapid publication on acceptance

- support for research data, including large and complex data types

- gold Open Access which fosters wider collaboration and increased citations

- maximum visibility for your research: over $100 \mathrm{M}$ website views per year

At BMC, research is always in progress.

Learn more biomedcentral.com/submissions 